\title{
Fatores críticos para o sucesso de um curso em EAD: a percepção dos acadêmicos
}

\author{
Josiani Aparecida Karpinski \\ Neirisleia Francisconi Del Mouro \\ Marcos de Castro \\ Luiz Fernando Lara
}

Resumo: Devido ao atual cenário competitivo em que as organizações estão inseridas, tanto públicas, quanto privadas, faz-se necessária a utilização de estratégias que permitam às empresas se destacarem das demais. Dentro desta perspectiva os fatores críticos de sucesso (FCS) se constituem de recursos necessários para que uma iniciativa venha a ser sustentada no longo prazo. Esta pesquisa busca identificar quais são os fatores críticos para o sucesso da oferta de um curso de especialização na modalidade $\mathrm{EaD}$, sob a perspectiva dos acadêmicos, utilizando-se como elementos de gestão que compõem os FCS, identificados no resgate teórico dos autores Rematal, Behar e Maçada (2009). A pesquisa é classificada como exploratória e quantitativa, utilizando-se o método de estudo de caso. Os resultados apontam que quatro fatores são essenciais para o sucesso da IES na modalidade EaD, podendo ser classificadas como: Ambiente e Organização Didático/Pedagógico (AODP); Reputação do Curso e da Instituição (RCI); Qualificação - professores-tutores (CPT) e Estrutura do curso (EC).

Palavras-chave: Fatores Críticos. Vantagem Competitiva. Educação a Distância.

\section{Critical factors to the success of a course in distance learning: the perception of academics}

Abstract: Due to the current competitive scenario which organizations are inserted, both public and private, it is necessary the use of strategies that will enable companies to stand out from the other ones. Within this perspective the critical success factors (CSF) constitute the necessary resources for an initiative that will be sustained in the long term. This research seeks to identify what are the critical factors for the success of the offer of a specialization course in distance learning mode, from the perspective of academics, using as management elements that make up the CSF, identified in the theoretical survey of authors Rematal, Behar and Maçada (2009). The research is classified as exploratory and quantitative, using the case study method. The results show four factors that are essential to the success of the IES in distance learning (DL), and can be classified as: Environment and Didactic / Pedagogical Organization (EPO); Reputation of the College and the Institution (RCI); Qualification teacher-tutors (QTT) and Course Structure (CE).

Key words: Critical factors. Competitive advantage. Distance learning. 


\section{Introdução}

Por que algumas empresas são mais bem sucedidas do que outras? As empresas podem possuir conjuntos diferentes de recursos e capacidades, mesmo que estejam competindo no mesmo setor e muitos desses fatores podem ser duradouros e se transformam em vantagem competitiva (BARNEY; HESTERLY, 2011).

Os estudos de estratégia se desenvolveram no anseio de explicar e encontrar uma forma de direcionar as organizações na busca pela vantagem competitiva. A compreensão destes fenômenos também é um anseio dos executivos e empreendedores (KAY, 1993).

A Teoria dos Recursos (Resource-based Theory - RBT) procura identificar as causas da performance superior da firma e da obtenção de uma vantagem competitiva sobre os demais concorrentes (PETERAF, 1993), utilizando para isso, a análise do ambiente interno, por meio de seus recursos heterogêneos e do potencial que cada um deles possui.

Considerando o atual cenário competitivo em que as organizações estão inseridas, tanto públicas, quanto privadas, faz-se necessária a utilização de estratégias que permitam às empresas se destacarem das demais. Os Fatores Críticos de Sucesso (FCS), quando identificados, podem ser gerenciados para a melhor utilização dos recursos disponíveis, permitindo desta forma, que a organização adote uma postura estratégica mais adequada em sua gestão.

Este artigo busca identificar quais são os fatores críticos mais relevantes e que contribuem para a vantagem competitiva do curso de especialização em gestão pública municipal, na modalidade à distância, em uma Universidade estadual do estado do Paraná, sob a perspectiva dos acadêmicos, nos quatro polos de apoio presencial, utilizando-se dos elementos de gestão que compõem os FCS, identificados teoricamente por Rematal, Behar e Maçada (2009).

A partir desta ótica, a contribuição deste estudo está em identificar recursos essenciais para o sucesso da atuação das instituições ofertantes da modalidade de ensino a distância, visando assim estabelecer estratégias que produzam melhorias no processo de ensino que disponibiliza ao seu público final.

\section{Referencial Teórico}

\subsection{Teoria de recursos da firma}

As organizações podem ser consideradas de fundamental importância para o ser humano, pois elas estão presentes em todos os momentos da vida do indivíduo que vive em sociedade. A análise dos fatores que as compõem não é uma tarefa simples, a complexidade é uma característica presente nas organizações devido ao aumento da competitividade em um mercado cada vez mais exigente (HALL, 1984).

O estudo realizado baseia-se na corrente de explanação da heterogeneidade de recursos das empresas, onde as pesquisas da teoria econômica e organizacional possuem o enfoque nos atributos das firmas de forma a explicar a forma diferenciada de utilização dos recursos e do desempenho, passando a ser conhecida como teoria da dependência de recursos (RBV - Resource Based View) (BARNEY; HESTERLEY, 2011). 
Diversos autores veem a VBR como ferramenta de gestão de recursos que visa proporcionar vantagem competitiva sustentada (PENROSE, 1959; DIERICKX; COLL, 1989; BARNEY, 1991; PETERAF, 1993 apud DOS SANTOS; DIAS, 2013, p. 5). Segundo Barney e Hesterly (2011) vantagem competitiva diz respeito à capacidade de uma empresa em gerar maior valor econômico do que suas concorrentes.

Barney (1991) entende que as organizações não podem esperar obter vantagens competitivas sustentáveis quando os recursos são uniformemente distribuídos entre todas as empresas concorrentes e sendo esses recursos altamente móveis (transferíveis). O estudo sobre vantagem competitiva preconiza que as empresas devem possuir a capacidade de gerir os recursos de forma a alcançar a heterogeneidade em relação às demais.

A Visão Baseada em Recursos (VBR) é uma perspectiva explicativa do comportamento estratégico, fundamentada na ideia de que seleção, obtenção e disposição de recursos e desenvolvimento de competências únicas ou de difícil imitação resultam em diferenciação e vantagem competitiva (CRUBELLATE; PASCUCCI; GRAVE, 2008).

De acordo com essa teoria, a principal fonte de vantagem competitiva está baseada nos recursos internos da organização (WERNERFELT, 1984; GHEMAWAT, 2000; OLIVEIRA JUNIOR, 2001; LEITE; PORSSE, 2003 apud REMATAL; BEHAR; MAÇADA, 2009, p. 5).

Grant (1991) reforça a importância dos recursos e das capacidades para a formulação de estratégias que sustentem uma vantagem competitiva, onde na seleção da estratégia devese identificar a que melhor explore os recursos e as capacidades existentes.

\subsection{Fatores Críticos de Sucesso}

Fatores Críticos de Sucesso (FCS) podem ser considerados como variáveis que possuem maior preponderância em alcançar melhores resultados. Rockart (1979) define o termo FCS como áreas específicas de uma organização em que seus resultados, quando satisfatórios, ajudarão a melhorar o desempenho da organização, tornando-a competitiva.

Fatores críticos de sucesso se constituem de recursos necessários para que uma iniciativa venha a ser sustentada no longo prazo, ou seja, se o método for aplicado como instrumento de gestão pode permitir a identificação de elementos de gestão e o compartilhamento de práticas bem sucedidas (REMATAL; BEHAR; MAÇADA, 2009).

Os recursos de uma organização podem ser fonte de vantagem competitiva, mas para isso devem ser identificados como tal. Neste contexto, pode-se considerar que os FCS são essenciais para o alcance dos objetivos que contribuem para o sucesso de uma organização, desde que identificados os indicadores como controle do desempenho crítico, pois é através deste desempenho que os recursos, as competências e os processos organizacionais podem comprometer os resultados esperados.

Assim, "Fatores críticos de sucesso são as habilidades e recursos que explicam os valores percebidos pelos clientes" (GRUNERT; ELLEGARD, 1992 apud MAGNANI, 2004, p. 77). A definição destes autores corrobora com o objetivo da pesquisa no que tange a identificar quais fatores contribuem para o sucesso do curso na percepção dos acadêmicos que nele estão inseridos. Porter (1980) e Day e Wesley (1988) indicam que a causa de diferenças no desempenho de empresas dentro de um mesmo negócio pode ser analisada em diversos níveis. Na visão desses autores, as diferenças podem ser tratadas de forma a serem reduzidas 
em dois fatores: o valor percebido pelos clientes nos produtos e serviços e o custo para criar estes fatores.

\subsection{Educação a Distância (EaD)}

As Instituições de Ensino Superior (IES) estão passando por profundas mudanças, relacionadas à democratização da educação e das novas tecnologias adotadas no processo de ensino-aprendizagem. Considerando esta nova realidade, exige-se dos gestores uma postura estratégica em busca de melhorias na gestão dos recursos existentes. Dentre as mudanças que vêm afetando a área da educação nos últimos anos estão as chamadas Tecnologias da Informação e Comunicação (TICs) que possibilitaram o avanço da Educação a Distância (EaD) que tem impactado na massificação do ensino, em todos os níveis, mas principalmente no ensino superior.

As características que a $\mathrm{EaD}$ apresenta contribuem claramente para a democratização do acesso ao conhecimento, amplia os espaços educacionais e diversifica o processo de aprendizagem. Neste contexto, as Instituições de Ensino Superior estão tendo que adaptar-se às mudanças e transformações, principalmente no que se refere às novas modalidades de ensino, que desafiam as estruturas tradicionais e estratégias. Segundo Oliveira (2006 apud REMATAL; BEHAR; MAÇADA, 2009, p. 2) "a lentidão de algumas instituições no seu processo decisório, a burocracia interna, a qualidade docente e discente, aliada ao amadorismo de aspectos relacionados à gestão contribuem para um desempenho pouco eficiente e eficaz". No entanto, algumas instituições vêm procurando incorporar uma nova postura estratégica em busca de melhorias nas suas estruturas e na gestão das mesmas.

A educação a distância é uma modalidade caracterizada por alguns estudiosos como a separação física do professor e aluno, a busca do aperfeiçoamento com melhor aproveitamento de tempo e avanços na carreira profissional. Neste sentido, Preti (1996) fala da evolução na estrutura das escolas e universidades para atender as novas exigências educacionais:

A crescente demanda por educação, devido não somente à expansão populacional como, sobretudo às lutas das classes trabalhadoras por acesso à educação, ao saber socialmente produzido, concomitantemente com a evolução dos conhecimentos científicos e tecnológicos está exigindo mudanças em nível da função e da estrutura da escola e da universidade (PRETI, 1996, p.11).

Devido à complexidade e à necessidade de uma abordagem sistêmica, referenciais de qualidade para projetos de cursos na modalidade a distância devem compreender categorias que envolvem fundamentalmente, aspectos pedagógicos, recursos humanos e infraestrutura (BRASIL. MEC, 2014a).

De acordo com Maia e Mattar (2007), a educação a distância atualmente é praticada nos mais variados setores. Ela é usada na educação básica, no ensino superior, em universidades abertas, universidades virtuais, treinamento governamentais, cursos abertos, livres etc.

A educação a distância é uma modalidade de ensino efetivada através da interatividade, das atribuições e avanços da tecnologia da informação e comunicação. De acordo com o Decreto $n^{\circ} 5.622$, art. $1^{\circ}$, caracteriza-se a EaD como modalidade educacional na 
qual a mediação didático-pedagógica nos processos de ensino e aprendizagem ocorre com a utilização de meios e tecnologias de informação e comunicação, com estudantes e professores desenvolvendo atividades educativas em lugares ou tempos diversos (BRASIL. MEC, 2014b).

$\mathrm{O}$ ambiente de modernização tecnológica tem provocado nos âmbitos das instituições públicas e privadas, a necessidade de maior qualificação de pessoal, para atuar dentro dos novos processos organizacionais e exercer as atividades gerenciais com maior eficiência.

Os cursos na área da Administração Pública, referentes ao Programa Nacional de Formação em Administração Pública (PNAP), no âmbito do Sistema UAB: bacharelado em Administração Pública, especialização em Gestão Pública, especialização em Gestão Pública Municipal e especialização Gestão em Saúde, têm por objetivo a formação e qualificação de pessoal de nível superior visando ao exercício de atividades gerenciais (BRASIL. CAPES, 2009).

\section{Procedimentos Metodológicos}

Diante do objetivo proposto, esta pesquisa classifica-se como exploratória, que segundo Vergara (2000) a investigação exploratória é realizada em área na qual há pouco conhecimento acumulado e sistematizado.

A estratégia de pesquisa adotada foi o estudo de caso, que de acordo com Yin (2010) trata-se de uma inquirição empírica que investiga um fenômeno contemporâneo dentro de um contexto da vida real, quando a fronteira entre o fenômeno e o contexto não é claramente evidente e onde múltiplas fontes de evidência são utilizadas. Sua principal função é a explicação sistemática dos fatos cujos dados devem ser representados sob a forma de tabelas, quadros, gráficos estatísticos e por meio da análise descritiva que os caracterizam (FACHIN, 2001).

Quanto aos meios de investigação foram utilizados dados primários e secundários e quanto à análise a pesquisa é caracterizada como quantitativa, pois tenta fazer uma mensuração precisa de algo (COOPER; SCHINDLER, 2011). Para a coleta de dados foi realizada a aplicação de questionários de preenchimento online, com 36 questões fechadas, utilizando-se escala Likert de cinco pontos. Segundo Botelho e Zouain (2009), a escala Likert apresenta uma escala de medida, solicitando que o entrevistado indique seu grau de concordância ou não, em relação a um objeto, sendo mais comumente usada para medir atitudes e opiniões. $\mathrm{O}$ instrumento de pesquisa foi aplicado no mês de outubro de 2014.

O universo constituiu-se de 225 (duzentos e vinte e cinco) acadêmicos do curso de especialização em gestão pública municipal, modalidade a distância, da Universidade Estadual do Centro-Oeste, distribuídos nos 04 (quatro) polos de apoio presencial, localizados nos municípios de Ivaiporã, São Mateus do Sul, Apucarana e Palmital, todos no Estado do Paraná. A amostra foi de 110 respondentes, correspondendo a 48,9\% do universo total da pesquisa. O número de evadidos no curso que não participaram da pesquisa foi de 115 .

O instrumento de pesquisa foi elaborado a partir do referencial teórico, cujo modelo é composto pelos FCS para a gestão de EaD via internet, escolhidos a partir do resgate teórico dos autores: Rematal, Behar e Maçada (2009), utilizados na validação do protocolo de estudo de caso, conforme Quadro 1. 


\section{Quadro 1 - Fatores críticos de sucesso para a Gestão de EaD via internet}

\begin{tabular}{|c|c|}
\hline Fator & Características \\
\hline Qualidade & $\begin{array}{l}\text { Propriedades que dão qualidade a um curso são: a efetividade, a eficiência, a pertinência, a } \\
\text { acessibilidade, a oportunidade, a atualidade e aceitabilidade (Mezomo, 1994; Testa, 2002; Oliveira, 2007; } \\
\text { Moore, 2008). }\end{array}$ \\
\hline Gestão & $\begin{array}{l}\text { Processo que possibilita o desenvolvimento de atividades com eficiência e eficácia, a tomada de decisão } \\
\text { considerando as ações que forem necessárias, e a escolha e verificação da melhor maneira de executá- } \\
\text { las (Abu-Duhou, } 2002 \text { citado por Rumble, 2003; Sartori, 2005; Moraes, 2007; Campos, 2007; MEC, 2008; } \\
\text { Moore, 2008; Ribas et al., 2008). }\end{array}$ \\
\hline Infraestrutura & $\begin{array}{l}\text { Refere às propriedades da instituição de ensino para alocar os recursos, tais como: prédios, instalações, } \\
\text { tecnologias e equipamentos necessários para possibilitar a interação entre os envolvidos (Testa, 2002; } \\
\text { Campos, 2007; MEC, 2008; Ribas et al., 2008). }\end{array}$ \\
\hline $\begin{array}{l}\text { Recursos } \\
\text { Humanos }\end{array}$ & $\begin{array}{l}\text { São intrínsecos às pessoas como sua criatividade, comportamento, educação e capacidades; incluem a } \\
\text { formação, a experiência e a capacitação dos atores envolvidos (Testa, 2002; MEC, 2008; Moore, 2008; } \\
\text { Ribas et al., 2008) }\end{array}$ \\
\hline $\begin{array}{l}\text { Recursos } \\
\text { Financeiros }\end{array}$ & $\begin{array}{l}\text { Envolve os critérios que orientam as decisões relativas à alocação e gerenciamento dos recursos (Testa, } \\
\text { 2002; MEC, 2008). }\end{array}$ \\
\hline $\begin{array}{l}\text { Modelo } \\
\text { Pedagógico }\end{array}$ & $\begin{array}{l}\text { É um sistema de premissas teóricas que embasa a arquitetura pedagógica (AP), sendo esta constituída } \\
\text { por aspectos organizacionais, conteúdo metodológicos e tecnológicos; e as estratégias para aplicação das } \\
\text { APs (Testa, 2002; Sartori, 2005; Moraes, 2007; Behar, 2009). }\end{array}$ \\
\hline $\begin{array}{l}\text { Avaliação de } \\
\text { Aprendizagem }\end{array}$ & $\begin{array}{l}\text { Definição dos recursos de aprendizagem utilizados para a avaliação dos alunos a partir do } \\
\text { acompanhamento do desempenho de suas atividades (Testa, 2002; Moraes, 2007). }\end{array}$ \\
\hline
\end{tabular}

Fonte: Elaborado a partir dos estudos de Rematal, Behar e Maçada (2009)

No que diz respeito à fase da análise de dados, foram utilizadas as técnicas estatísticas alicerçadas na análise fatorial exploratória, por meio da utilização do Statistical Package for the Social Sciences (SPSS). A utilização da Análise Fatorial Exploratória é a análise mais adequada para a extração de fatores de um conjunto de variáveis (FIELD, 2009).

\section{Apresentação e Análise dos Dados}

A seguir, serão descritos os resultados da pesquisa, iniciando-se pela apresentação dos dados referente ao perfil dos pesquisados, em sequência a abordagem referente ao curso e por último a descrição e análises dos fatores críticos de sucesso.

\subsection{Perfil dos acadêmicos}

A primeira parte do questionário compreendeu a identificação do perfil dos acadêmicos que compõem o universo desta pesquisa, em nove questões. Dentre esses indícios de identificação estavam o polo de origem do respondente, a idade, a condição civil, o sexo, os motivos que influenciaram na escolha do curso, o grau de satisfação e a importância do curso para sua vida profissional e pessoal. Os dados relacionados ao polo de origem dos participantes da pesquisa estão dispostos na tabela 2. 
Tabela 2 - Perfil dos acadêmicos pesquisados

\begin{tabular}{cccr}
\hline Variável & Escala & N & $\%$ \\
\hline \multirow{2}{*}{ Polo que estuda } & Apucarana & 35 & $32 \%$ \\
& Ivaiporã & 12 & $11 \%$ \\
& Palmital & 37 & $33 \%$ \\
& São Mateus do Sul & 26 & $24 \%$ \\
\hline \multirow{2}{*}{ Gênero } & Masculino & 39 & $35 \%$ \\
& Feminino & 71 & $65 \%$ \\
\hline \multirow{2}{*}{ Idade } & 18 a 25 anos & 5 & $5 \%$ \\
& 26 a 33 anos & 65 & $59 \%$ \\
& 34 a 41 anos & 19 & $17 \%$ \\
& Acima de 41 anos & 21 & $19 \%$ \\
\hline \multirow{2}{*}{ Estado civil } & Solteiro(a) & 32 & $29 \%$ \\
& Casado(a) & 55 & $50 \%$ \\
& Viúvo(a) & 5 & $5 \%$ \\
& União Estável & 9 & $8 \%$ \\
& Outro & 9 & $8 \%$ \\
\hline
\end{tabular}

Fonte: Elaborado pelos autores com dados coletados na pesquisa de campo (2014)

Analisando-se a tabela 2 é possível verificar que 33\% dos participantes da amostra estão vinculados ao polo de Palmital, 32\% o polo de Apucarana, 24\% o polo de São Mateus do Sul e apenas $11 \%$ dos respondentes são do polo de Ivaiporã.

Nesse sentido, as informações obtidas na tabela de perfil, já demonstra influência no fator qualidade, pois explicitam a regionalização que o curso apresenta, relaciona-se ao fator infraestrutura do curso e a abrangência da faixa etária compreendida. Ainda que muitas pessoas acreditem que a educação a distância seja uma modalidade de ensino de baixa qualidade, tal conceito está mudando, visto que os cursos oferecidos por este sistema estão sendo vistos como um meio de alguns indivíduos retornarem aos estudos, já que estes permitem o acesso por pessoas que possuem tempo limitado, e possibilita o estudo em casa, com a utilização da internet, por exemplo (ISHIDA; STEFANO; ANDRADE, 2013).

Com relação à faixa etária dos acadêmicos pesquisados, verificou-se que $59 \%$ da amostra está concentrada na faixa de idade entre 26 e 33 anos.

O nível de escolaridade formal da população brasileira tem se elevado continuamente no decorrer dos anos, devido à competitividade no mercado de trabalho. Nota-se que o público jovem está buscando aperfeiçoamento na modalidade a distância com o intuito de maximizar melhor o tempo disponível e conciliar com outras atividades do seu cotidiano. De acordo com os dados do IBGE referente aos censos demográficos 2000/2010, pode-se observar que a distribuição de pessoas acima de 25 anos ou mais de idade no Ensino Superior, sofreu um aumento de mais de 58\%, 6,8\% em 2000 e 10,8\% em 2010 (IBGE, 2014a).

Com relação ao estado civil, foi possível identificar que $50 \%$ dos respondentes são casados. Percebe-se que a modalidade a distância permite que um número maior de pessoas tenha acesso à educação, onde o aluno passa a ser sujeito ativo em sua formação e faz com 
que o processo de aprendizagem se desenvolva no mesmo ambiente em que se trabalha e vive, alcançando assim uma formação entre teoria e prática, ligada à experiência em que se pretende aperfeiçoar (LARA, 2009).

Quanto ao sexo dos participantes do curso em análise, 65\% dos respondentes são do sexo feminino e 35\% masculino. Na literatura, a associação entre a escolaridade e a participação das mulheres no mercado de trabalho é intensa e observa-se um aumento significativo do nível de instrução da população, principalmente das mulheres, 39\% das quais passam a ter mais de 9 anos de estudo, em comparação a 35\% dos homens (FUNDAÇÃO CARLOS CHAGAS, 2014). Segundo o Censo do IBGE de 2010, em dez anos, o nível de instrução das mulheres continuou mais elevado que o dos homens [...] (IBGE, 2012).

No que diz respeito à área de atuação profissional dos pesquisados, os dados obtidos estão apresentados no gráfico 1. Pelas respostas, foi possível levantar que $86 \%$ dos respondentes são da área pública e somente $11 \%$ estão em outras áreas, e 3\% não trabalham. Esse resultado corrobora o objetivo do curso e seu público-alvo: “O curso de Gestão Pública Municipal destina-se aos portadores de diploma de curso superior que exercem atividades em órgãos públicos municipais ou do terceiro setor ou que tenham aspirações ao exercício de função pública" (UNICENTRO, 2014a).

Outro dado obtido pelo levantamento realizado pelo IBGE é que as mulheres (11\%) que concluem o curso superior supera o número de homens (10,5\%), em 4,8\%. (IBGE, 2014b). Outro fator é a inserção da mulher no mercado de trabalho. Quanto à inserção da mulher no mercado de trabalho, a taxa de atividade mostra que a proporção da população em idade ativa (PIA, de 16 anos ou mais) que se encontra trabalhando ou procurando trabalho, entre 2000 e 2010 apresentou um aumento entre as mulheres, de 50,1\% para 54,6\% respectivamente (IBGE, 2014b).

\section{Gráfico 1- Área de atuação profissional}

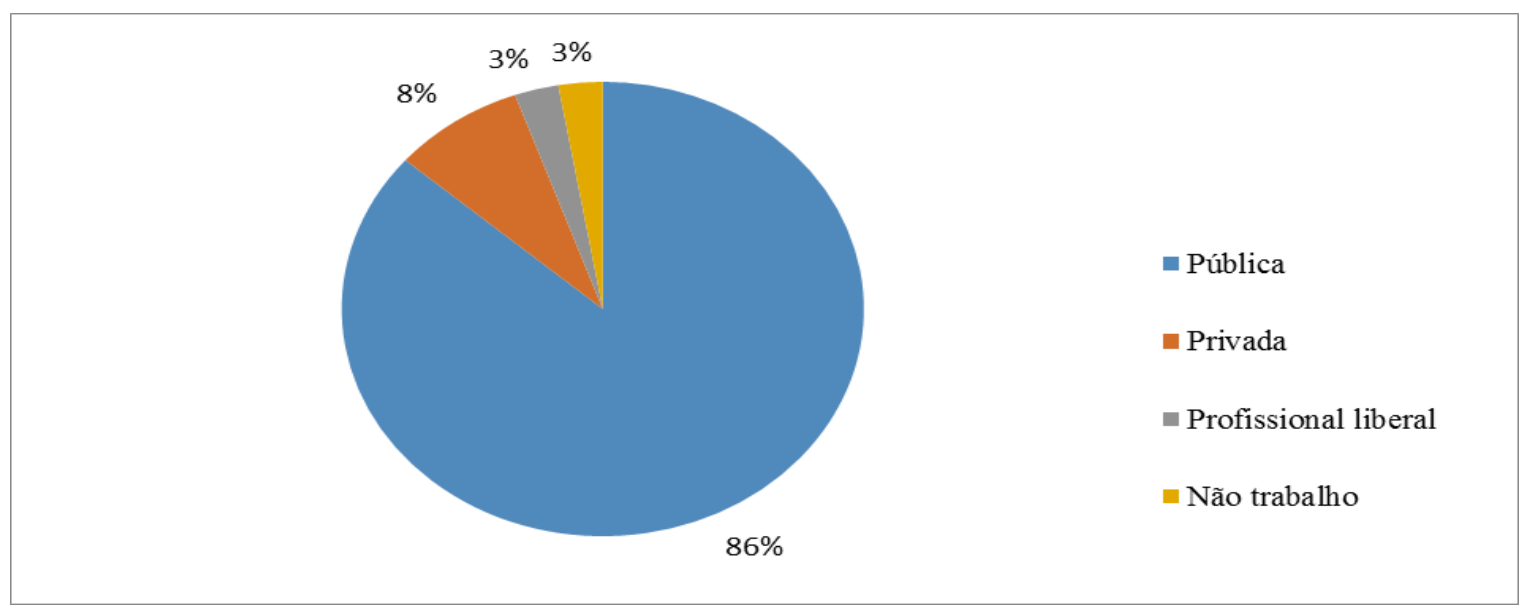

Fonte: Elaborado pelos autores com dados coletados na pesquisa de campo (2014)

Há um debate constante no mundo acadêmico sobre qual o perfil do indivíduo que é levado a estudar pela modalidade a distância. Esses alunos que estudam on-line geralmente são adultos, pois essa espécie de aprendizagem, que se dá em qualquer lugar e a qualquer hora, permite-lhes continuar trabalhando em turno integral sem deixar de dar atenção à 
família. O aluno on-line 'típico' é geralmente descrito como alguém que tem mais de 25 anos, está empregado, com alguma educação superior em andamento, podendo ser tanto do sexo masculino, quanto do feminino (GILBERT, 2001 apud PALLOF; PRATT, 2004).

\subsection{Abordagens sobre o curso}

A seguir, serão apresentados os dados referentes ao motivo da escolha, o nível de importância para a vida profissional e pessoal, o grau de satisfação em relação ao curso, bem como a área de atuação dos acadêmicos pesquisados. A tabela 3 apresenta os motivos pelos quais os alunos optaram pelo curso de Gestão Pública Municipal na modalidade EaD.

Tabela 3 - Motivos de Escolha do Curso de Gestão Pública Municipal modalidade EaD

\begin{tabular}{ll}
\hline Escala & $\%$ \\
\hline Trabalho em instituição pública e necessito de um curso na minha área de atuação. & $59 \%$ \\
Não tenho condições de fazer um curso de pós presencial. & $3 \%$ \\
Por ser um curso gratuito. & $10 \%$ \\
Por ser ofertado próximo de minha residência. & $4 \%$ \\
Para ocupar o tempo ocioso. & $2 \%$ \\
Flexibilidade para estudar. & $13 \%$ \\
Possuo vínculo com organizações da sociedade civil que necessitam de conhecimentos em gestão pública: & $2 \%$ \\
associações, sindicatos, ONGs, partidos políticos, etc. & $7 \%$ \\
Outros & $\mathbf{1 0 0}$ \\
\hline Total & \\
\hline
\end{tabular}

Fonte: Elaborado pelos autores com dados coletados na pesquisa de campo (2014)

Conforme pode ser verificado, 59\% dos pesquisados trabalham em instituição pública e necessitam de um curso ligado diretamente às suas áreas de atuação. O papel reservado aos cursos de Especialização em Gestão Pública Municipal é de grande importância, pois visa capacitar os agentes especialistas egressos, gestores e formuladores de políticas públicas a intervirem na realidade social, política e econômica, nas mais diversas atividades em órgãos públicos municipais ou do terceiro setor ou no exercício de função pública (UNICENTRO, 2014a).

Na tabela 4 são apresentados os dados relacionados ao grau de importância que o curso trará para o desempenho da vida profissional dos participantes da pesquisa.

Tabela 4 - Grau de importância do curso na vida profissional e pessoal

\begin{tabular}{|c|c|}
\hline Escala & $\%$ \\
\hline Nada Importante & $3 \%$ \\
\hline Pouco Importante & $4 \%$ \\
\hline Indiferente & $14 \%$ \\
\hline Importante & $26 \%$ \\
\hline Muito Importante & $53 \%$ \\
\hline Total & 100 \\
\hline
\end{tabular}

Fonte: Elaborado pelos autores com dados coletados na pesquisa de campo (2014) 
Com relação ao nível de importância que o curso de especialização terá para a vida profissional e pessoal, observa-se que apenas 7\% afirmam não ser "nada importante" ou "pouco importante". A maior fatia da amostra (80\%) informou que o curso é importante para suas vidas.

A seguir, será apresentado no gráfico 2 o grau de satisfação dos acadêmicos em relação a esse curso.

\section{Gráfico 2 - Grau de Satisfação o Curso de Gestão Pública Municipal EaD}

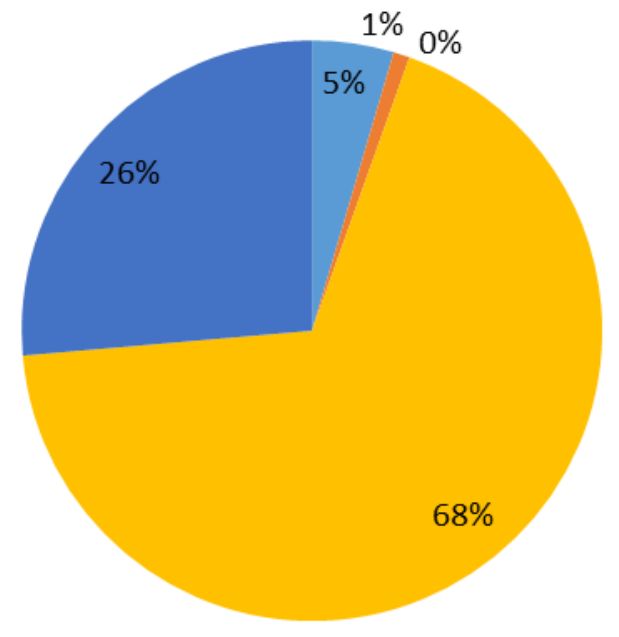

Muito Insatis feito

Insatisfeito

Indiferente

Satisfeito

Muito Satisfeito

Fonte: Elaborado pelos autores com dados coletados na pesquisa de campo (2014)

O gráfico 2 demonstra, portanto, que 94\% dos respondentes estão satisfeitos com esse curso de especialização na modalidade ensino a distância. Este é um ponto positivo que indica haver um alinhamento entre a satisfação e as expectativas dos estudantes do curso. Dessa forma, esse resultado torna-se um indicativo para que a UNICENTRO por meio do seu setor responsável pela oferta de cursos na modalidade $\mathrm{EaD}$, possa estar pensando as estratégias de reoferta desse curso em específico. Interessante aqui já indicar uma possível pesquisa com egressos desse curso que possa investigar o quanto, efetivamente, o mesmo teve influência na sua vida profissional e pessoal.

\subsection{Análises dos fatores críticos de sucesso (fcs)}

Esta parte da pesquisa desdobrou-se em um conjunto de 28 variáveis, exceto as questões 06 e 23 (descartadas por apresentar carga fatorial isolada, ou seja, não se agrupavam a nenhum grupo de fatores), sendo submetidas à Análise Fatorial. Foi utilizado para essa análise o programa estatístico SPSS da IBM.

As variáveis que não atenderam aos níveis de Measure of Sampling Adequacy (MSA) e Comunalidades de pelo menos 0,5 , foram individualmente excluídas partindo-se de menor valor e, por processamentos sucessivos a cada exclusão, obteve-se o modelo com 26 variáveis retidas. 
O teste utilizado para verificar a viabilidade da realização da análise fatorial é o teste de Kaiser-Mayer-Olkin (KMO). Segundo Kaiser (1974 apud FIELD, 2009, p. 579), para o KMO “[...] os valores entre 0,5 e 0,7 são medíocres, valores entre 0,7 e 0,8 são bons, valores entre 0,8 e 0,9 são ótimos e valores acima de 0,9 são excelentes". O resultado do teste apresentado pelo SPSS para o KMO foi 0,907 (approx. Chi-Square 2112,534 df. 325, sig. 0,000). Em outras palavras, "devemos estar confiantes de que a análise dos fatores é apropriada para esses dados" (FIELD, 2009, p. 579).

Na tabela 5 são apresentados os fatores retidos tendo como critério o número arbitrado de 4 fatores analisados pelo método de extração: Análise do Componente principal, considerando que os fatores retidos são aqueles que apresentaram autovalores (eigenvalues) acima de 1, de acordo com o sugerido pela literatura (FIELD, 2009). Os 4 fatores (dimensões) combinados explicam $67,65 \%$ das variâncias do conjunto total (26) das variáveis que foram utilizadas no modelo.

Tabela 5 - Variância Total Explicada

\begin{tabular}{|c|c|c|c|c|c|c|c|c|c|}
\hline \multirow[b]{2}{*}{ Fat } & \multicolumn{3}{|c|}{ Valores próprios iniciais } & \multicolumn{3}{|c|}{$\begin{array}{l}\text { Somas da extração dos } \\
\text { carregamentos ao quadrado }\end{array}$} & \multicolumn{3}{|c|}{$\begin{array}{l}\text { Somas rotativas de } \\
\text { carregamentos ao quadrado }\end{array}$} \\
\hline & Total & $\begin{array}{c}\text { \% de } \\
\text { variância }\end{array}$ & $\begin{array}{c}\% \\
\text { Acumulado }\end{array}$ & Total & $\begin{array}{c}\text { \% de } \\
\text { variância }\end{array}$ & $\begin{array}{c}\% \\
\text { Acumulado }\end{array}$ & Total & $\begin{array}{c}\text { \% de } \\
\text { variância }\end{array}$ & $\begin{array}{c}\% \\
\text { Acumulado }\end{array}$ \\
\hline 1 & 13,388 & 51,491 & 51,491 & 13,388 & 51,491 & 51,491 & 5,261 & 20,235 & 20,235 \\
\hline 2 & 1,674 & 6,438 & 57,929 & 1,674 & 6,438 & 57,929 & 4,637 & 17,835 & 38,070 \\
\hline 3 & 1,292 & 4,968 & 62,897 & 1,292 & 4,968 & 62,897 & 4,160 & 16,000 & 54,070 \\
\hline 4 & 1,237 & 4,758 & 67,655 & 1,237 & 4,758 & 67,655 & 3,532 & 13,586 & 67,655 \\
\hline 5 & 0,957 & 3,681 & 71,336 & & & & & & \\
\hline 6 & 0,826 & 3,177 & 74,513 & & & & & & \\
\hline 7 & 0,705 & 2,710 & 77,224 & & & & & & \\
\hline 8 & 0,666 & 2,562 & 79,785 & & & & & & \\
\hline 9 & 0,599 & 2,303 & 82,088 & & & & & & \\
\hline 10 & 0,519 & 1,997 & 84,085 & & & & & & \\
\hline 11 & 0,512 & 1,970 & 86,055 & & & & & & \\
\hline 12 & 0,454 & 1,746 & 87,801 & & & & & & \\
\hline 13 & 0,397 & 1,526 & 89,326 & & & & & & \\
\hline 14 & 0,382 & 1,470 & 90,796 & & & & & & \\
\hline 15 & 0,331 & 1,275 & 92,071 & & & & & & \\
\hline 16 & 0,322 & 1,238 & 93,309 & & & & & & \\
\hline 17 & 0,303 & 1,165 & 94,474 & & & & & & \\
\hline 18 & 0,243 & 0,935 & 95,409 & & & & & & \\
\hline 19 & 0,227 & 0,873 & 96,282 & & & & & & \\
\hline 20 & 0,211 & 0,811 & 97,093 & & & & & & \\
\hline 21 & 0,195 & 0,748 & 97,841 & & & & & & \\
\hline 22 & 0,161 & 0,621 & 98,462 & & & & & & \\
\hline 23 & 0,131 & 0,504 & 98,966 & & & & & & \\
\hline 24 & 0,109 & 0,419 & 99,385 & & & & & & \\
\hline 25 & 0,090 & 0,347 & 99,733 & & & & & & \\
\hline 26 & 0,069 & 0,267 & 100,000 & & & & & & \\
\hline
\end{tabular}

Fonte: Elaborado pelos autores com dados coletados na pesquisa de campo (2014) 
Na Tabela 6 é exibida a Matriz de Componente Rotativa com as respectivas cargas fatoriais, tendo por base o método de Análise dos Componentes Principais da matriz de correlações, com rotação varimax e normalização de Kaiser. A matriz foi convergida em 4 iterações (HAIR JUNIOR et al., 2005; MAROCO, 2007).

Tabela 6 - Matriz de Componente Rotativa

\begin{tabular}{|c|c|c|c|c|c|}
\hline & \multirow{2}{*}{ Variáveis / indicadores retidos } & \multicolumn{4}{|c|}{ Fatores retidos e Cargas Fatoriais } \\
\hline & & 1 & 2 & 3 & 4 \\
\hline Q19 & Plataforma moodle & 0,828 & & & \\
\hline Q12 & Utilização do sistema moodle & 0,811 & & & \\
\hline Q18 & Apoio técnico operacional & 0,787 & & & \\
\hline Q02 & Forma com que o curso é coordenado & 0,638 & & & \\
\hline Q07 & Organização do curso & 0,622 & & & \\
\hline Q27 & Atividades pedagógicas & 0,560 & & & \\
\hline Q22 & Conteúdo do programa & 0,520 & & & \\
\hline Q25 & Imagem da Instituição & & 0,776 & & \\
\hline Q24 & Certificação (diploma) & & 0,745 & & \\
\hline Q26 & Credibilidade do programa & & 0,720 & & \\
\hline Q14 & Qualificação dos professores & & 0,656 & & \\
\hline Q20 & Gratuidade do curso & & 0,635 & & \\
\hline Q16 & Nível de exigência do curso & & 0,580 & & \\
\hline Q28 & Avaliação dos alunos & & 0,573 & & \\
\hline Q15 & Qualificação dos tutores (presenciais e a distância) & & & 0,783 & \\
\hline Q01 & Atendimento Tutores Presenciais & & & 0,753 & \\
\hline Q17 & Atendimento dos tutores a distância & & & 0,654 & \\
\hline Q11 & Interação com os professores & & & 0,579 & \\
\hline Q05 & Atendimento no polo (coordenação e secretaria) & & & 0,525 & \\
\hline Q10 & Biblioteca do polo & & & & 0,763 \\
\hline Q13 & Ambiente físico do curso no polo & & & & 0,723 \\
\hline Q03 & Materiais didáticos impressos & & & & 0,639 \\
\hline Q21 & Laboratório de informática & & & & 0,502 \\
\hline
\end{tabular}

Fonte: Elaborado pelos autores com dados coletados na pesquisa de campo (2014)

Com relação às cargas fatoriais, observa-se que foram satisfatórias $(\mathrm{CF}>0,6) \mathrm{em}$, praticamente, todas as variáveis, excetuando-se as questões Q05, Q11, Q16, Q21, Q22, Q27 e Q28.

A partir da matriz de componente rotativa, com rotação convergida de sete fatores do modelo teórico, foram extraídos quatro fatores que apresentaram correlação evidente para o sucesso do curso pesquisado. Na Tabela 7 é apresentada a síntese da análise fatorial, com seus principais pressupostos e densidade das dimensões retidas. A densidade das dimensões foi medida pela análise estatística representada pela chamada carga fatorial, dada à dimensão 
adotada como critério dos valores com carga acima de 0,5. Quanto mais alta a carga fatorial, maior correlação representativa dos valores agrupados.

Tabela 7 - Variáveis componentes dos fatores críticos de sucesso

\begin{tabular}{|c|c|c|c|}
\hline Fatores & Var & Carga fatorial & \\
\hline \multirow{8}{*}{$\begin{array}{c}\text { Ambiente e Organização Didático } \\
\text { Pedagógico (AODP) }\end{array}$} & Q19 & Plataforma moodle & 0,828 \\
\hline & Q12 & Utilização do sistema moodle & 0,811 \\
\hline & Q18 & Apoio técnico operacional & 0,787 \\
\hline & & & 0638 \\
\hline & Q02 & Forma com que o curso é coordenado & 0,638 \\
\hline & Q07 & Organização do curso & 0,622 \\
\hline & Q27 & Atividades pedagógicas & 0,560 \\
\hline & Q22 & Conteúdo do programa & 0,520 \\
\hline \multirow{7}{*}{ Reputação do curso e da Instituição (RCl) } & Q25 & Imagem da Instituição & 0,776 \\
\hline & Q24 & Certificação (diploma) & 0,745 \\
\hline & Q26 & Credibilidade do programa & 0,720 \\
\hline & Q14 & Qualificação dos professores & 0,656 \\
\hline & Q20 & Gratuidade do curso & 0,635 \\
\hline & Q16 & Nível de exigência do curso & 0,580 \\
\hline & Q28 & Avaliação dos alunos & 0,573 \\
\hline \multirow{5}{*}{ Qualificação professores-tutores (QPT) } & Q15 & Qualificação dos tutores (presenciais e a distância) & 0,783 \\
\hline & Q01 & Atendimento Tutores Presenciais & 0,753 \\
\hline & Q17 & Atendimento dos tutores a distância & 0,654 \\
\hline & Q11 & Interação com os professores & 0,579 \\
\hline & Q05 & Atendimento no polo (coordenação e secretaria) & 0,525 \\
\hline \multirow{4}{*}{ Estrutura do curso (EC) } & Q10 & Biblioteca do polo & 0,763 \\
\hline & Q13 & Ambiente físico do curso no polo & 0,723 \\
\hline & Q03 & Materiais didáticos impressos & 0,639 \\
\hline & Q21 & Laboratório de informática & 0,502 \\
\hline
\end{tabular}

Fonte: Elaborado pelos autores com dados coletados na pesquisa de campo (2014)

A partir das variáveis recrutadas, demonstradas na Tabela 6 , em cada um dos fatores (dimensões), procedeu-se a denominação desses conjuntos demonstrados detalhadamente na Tabela 7, conforme definido no modelo teórico, o desempenho foi caracterizado como uma variável latente constituído por quatro fatores:

a) Fator 1: Ambiente e Organização Didático Pedagógico (AODP), refere-se ao conjunto de variáveis composto pelas questões Q19, Q12, Q18, Q02, Q07, Q27 e Q22. Para definir a contribuição de cada indicador para o desempenho, optou-se por estabelecer os pesos baseados nas cargas fatoriais de cada indicador, quanto mais alta a carga fatorial maior a correlação entre o grupo. Os FCS relacionados ao fator ambiente e organização didático/pedagógico dispõem de $31 \%$ do total da carga fatorial dos quatro fatores, o qual é composto pelas seguintes variáveis: plataforma Moodle (17\%); utilização do sistema Moodle (17\%); apoio técnico operacional (17\%); forma com que o curso é coordenado (13\%); organização do curso (13\%); atividades pedagógicas (12\%) e conteúdo do programa (11\%).

Observa-se que o primeiro fator contempla principalmente a interatividade entre os professores, tutores e acadêmicos, centrada no Ambiente virtual de Aprendizagem, em que a tecnologia proporciona a interação e condição de criar um processo de aprendizado motivador e facilitador da geração de conhecimento. Para que todo o processo de ensino-aprendizado 
ocorra de forma satisfatória, a equipe multidisciplinar (docentes, tutores e pessoal técnico) deve atuar em consonância e de forma integrada.

b) Fator 2: Reputação do curso e da Instituição (RCI), refere-se ao conjunto de variáveis composto pelas seguintes questões: Q25, Q24, Q26, Q14, Q20 e Q16, Q28, onde apresentam grande representatividade no que se refere à imagem da instituição, a qual representa $17 \%$ (de toda a carga fatorial do grupo no fator 2) na percepção dos acadêmicos. Observa-se que existe uma preocupação por parte da instituição em disponibilizar aos alunos do curso a distância, um nível de educação com qualidade e eficiência, visando à reputação do curso e da instituição. Os FCS relacionados com a reputação do curso e da instituição destacam-se: imagem da instituição (17\%); certificação (diploma) (16\%); credibilidade do programa (15\%); qualificação dos professores (14\%); gratuidade do curso (14\%); nível de exigência do curso (12\%) e avaliação dos alunos (12\%), que juntos representam $30 \%$ do total da carga fatorial dos quatro fatores. De acordo com os Indicadores de qualidade do MEC a Instituição de Ensino recebeu a pontuação 4 e obteve selos de qualidade em 27 cursos, de acordo com o Guia do Estudante (UNICENTRO, 2014b).

c) Fator 3: Qualificação professores-tutores (QPT), refere-se ao conjunto de variáveis composto pelas seguintes questões: Q15, Q01, Q17, Q11 e Q05, neste contexto identificou-se que a qualificação é centrada muito no corpo docente e nos tutores que estão envolvidos no curso, indicando que este conjunto de variáveis representa $21 \%$ do total da carga fatorial dos 4 fatores. Os aspectos associados ao FCS de qualificação dos professores-tutores referem-se à qualificação dos tutores, presenciais e a distância (24\%); atendimento tutores presenciais (23\%); atendimento dos tutores a distância (20\%); interação com os professores (18\%) e atendimento no polo - coordenação e secretaria (16\%).

Devido à complexidade observada no processo ensino-aprendizagem na modalidade a distância, tanto o quadro docente quanto o corpo de tutores, desempenham um papel muito importante no processo educacional, sendo fundamental a participação ativa destes atores na prática pedagógica, bem como a necessidade de capacitação no domínio do conteúdo, das mídias de comunicação e conhecimento do processo pedagógico e avaliativo.

d) Fator 4: Estrutura do curso (EC), faz referência ao conjunto de variáveis composto pelas seguintes questões: Q10, Q13, Q03 e Q21, que identificam a estrutura física oferecida no polo de oferta do curso, representando $17 \%$ do total da carga fatorial nos 4 fatores, evidenciada pelas variáveis associadas ao FCS referem-se à biblioteca do polo (29\%); ambiente físico do curso no polo (28\%); materiais didáticos (24\%) impressos e laboratório de informática (19\%). Este fator corrobora com o modelo teórico citado no quadro 1 pelas características de infraestrutura, a qual faz referência às propriedades da instituição de ensino para alocar os recursos, tais como: prédios, instalações, tecnologias e equipamentos necessários para possibilitar a interação entre os envolvidos (CAMPOS, 2007; MEC, 2008; RIBAS et al., 2008; TESTA, 2002 apud REMATAL; BEHAR; MAÇADA, 2009).

Em atendimento às exigências legais, Decreto 5.622 de 19 de dezembro de 2005, parágrafo 1, é prevista a obrigatoriedade de momentos presenciais para algumas atividades. A infraestrutura do curso deve prover momentos de encontros presenciais, bem como dispor de polos de apoio para as atividades de estudo, biblioteca, laboratório de informática com acesso à Internet, secretaria e salas para os exames presenciais (BRASIL. MEC, 2014b). 
Os polos de apoio presencial devem contar com estruturas essenciais, cuja finalidade é assegurar a qualidade dos conteúdos ofertados (BRASIL. MEC, 2014a).

\section{Considerações finais}

A sociedade contemporânea tem passado por várias mudanças, principalmente na área da educação, em que a complexidade em relação ao espaço e tempo, como também a tecnologia, fazem parte do dia a dia.

De acordo com o perfil dos acadêmicos do curso de especialização na modalidade EaD pesquisados, pode-se ratificar as pesquisas anteriores realizadas por Gilbert (2001 apud PALLOF; PRATT, 2004) que os alunos que estudam em curso universitário on-line geralmente são adultos, homens e mulheres e que esta modalidade permite-lhes continuar trabalhando em turno integral sem deixar de dar atenção à família, pois na pesquisa identificou-se que 50\% dos respondentes são casados. O aluno on-line 'típico' é geralmente descrito como alguém que tem mais de 25 anos, neste caso, observou-se que a maioria apresenta idade entre 26 a 33 anos, grande parte trabalha na área relacionada ao objeto de estudo do curso (86\%) e o curso de especialização é importante por contribuir para a capacitação profissional dos pesquisados.

Embora a modalidade em EaD possua características próprias, a partir da identificação dos elementos fundamentais deste processo em específico, é possível gerenciar melhor os recursos de forma que a instituição possa alcançar vantagem competitiva.

O objetivo deste trabalho foi alcançado quando por meio da análise fatorial, foram identificados os quatro principais fatores críticos de sucesso da instituição de ensino pesquisada: ambiente e organização didático/pedagógico (AODP); reputação do curso e da instituição (RCI); qualificação professores-tutores (QPT) e estrutura do curso (EC). Fatores estes que evidenciam a qualidade e, assim reafirmam que os FCS existem e contribuem significativamente para o sucesso do curso, além de oferecer fatores que possuem prevalência em alcançar resultados satisfatórios e recursos suficientes, capazes de torná-lo competitivo. Os resultados estão de acordo com os estudos sobre Fatores Críticos de Sucesso em EaD, quando classificam as categorias referenciais de qualidade, como fundamentalmente aspectos pedagógicos, recursos humanos e infraestrutura (BRASIL. MEC, 2014a).

O estudo apresentado permite a comprovação empírica da VBR e dos FCS, possibilitando que estratégias sejam desenvolvidas com vistas a melhorar, cada vez mais, o posicionamento da instituição com relação ao ambiente em que opera, bem como, solidificar esse curso como um dos principais do seu portfólio.

Contudo é importante salientar algumas limitações da pesquisa, entre elas, a limitação de generalização, por tratar-se de um estudo que incluiu apenas um curso na modalidade e, assim apresentar os resultados aos gestores dos cursos na instituição para formem sua opinião sobre tudo, no aspecto da tomada de decisão em modificar a estrutura com base no estudo. Dessa forma, sugere-se que sejam realizados novos estudos sobre o tema Fatores Críticos de Sucesso, que estejam relacionadas, por exemplo, outras Instituições que trabalham com a modalidade à distância, a fim de confirmar ou refutar os resultados apresentados. 


\section{Referências}

BARNEY, J. B. Looking inside form competitive advantage. The Academy of Management Executive, v. 9, n. 4, p. 49-61, 1991. Disponível em: <https://www.jstor.org/stable/4165288>. Acesso em: 03 set. 2014.

BARNEY, J. B.; CLARK, D. N. Resource-based theory: creating and sustaining competitive advantage. NY: Oxford University, 2007.

BARNEY, J. B.; HESTERLY, W. Administração estratégica e vantagem competitiva. São Paulo: Pearson Prentice Hall, 2011.

BOTELHO, D.; ZOUAIN, D. M. (Org.). Pesquisa quantitativa em administração. São Paulo: Atlas, 2009.

BRASIL. CAPES. Programa Nacional de Formação em Administração Pública. 2009. Disponível em: <http://www.capes.gov.br/educacao-a-distancia/pnap>. Acesso em: 21 out. 2014.

BRASIL. MEC. Referenciais de qualidade para Educação Superior a Distância. Brasília. 2007. Disponível em: <http://portal.mec.gov.br/seed/arquivos/pdf/legislacao/refead1.pdf〉. Acesso em: 16 nov. 2014a.

BRASIL. MEC. Decreto no 5.622 de 19 de dezembro de 2005 do Ministério da Educação. Disponível em: <http://portal.mec.gov.br/seed/arquivos/pdf/dec_5622.pdf>. Acesso em: 15 nov. 2014b.

COOPER, D. R.; SCHINDLER, P. S. Métodos de pesquisa em administração. 10. ed. Porto Alegre: Bookman, 2011.

CRUBELLATE, J. M; PASCUCCI, L; GRAVE, P. S. Contribuições para uma visão baseada em recursos legítimos. Revista de Administração de Empresas, São Paulo, v. 48, n. 4, 2008. <Disponível em: http://www.scielo.br/scielo.php?script=sci_arttext\&pid=S0034$75902008000400002>$. Acesso em: 25 set. 2014.

DAY, G. S.; WENSLEY, R. Assessing advantage: a framework for diagnosing competitive superiority. Journal of Marketing, n. 52, apr. 1988. Disponível em: < https://www.jstor.org/stable/1251261>. Acesso em 09 mai. 2014.

DOS SANTOS, I. B.; DIAS, C. N. Gestão estratégica: a VBR para análise interna de empresas emergentes em mercados de alta tecnologia. Revista Negócios em Projeção, Brasília, dez. 2013. Disponível em:

<http://revista.faculdadeprojecao.edu.br/index.php/Projecao1/article/view/314>. Acesso em: 20 out. 2014.

FACHIN, O. Fundamentos de metodologia. 3. ed. São Paulo: Saraiva, 2001.

FIELD, A. Descobrindo a estatística usando o SPSS. 2. ed. Porto Alegre: Artmed, 2009. 
FUNDAÇÃO CARLOS CHAGAS. Mulheres brasileiras, educação e trabalho. Disponível em: <http://www.fcc.org.br/bdmulheres/serie3.php?area=series>. Acesso em: 13 nov. 2014.

GRANT, R. M. The resource-based theory of competitive advantage: implications for strategy formulation. California Management Review, Califórnia, v. 33, 1991.

HAIR JUNIOR, J. F. et al. Análise multivariada de dados. Porto Alegre: Bookman, 2005.

HALL, R. H. Organização: estruturas e processos. 3. ed. Rio de Janeiro: Prentice Hall do Brasil, 1984.

INSTITUTO BRASILEIRO DE GEOGRAFIA E ESTATÍSTICA - IBGE. Censo

Demográfico 2010: Trabalho e Rendimento, Educação e Deslocamento. Rio de Janeiro, 2012. Disponível em:

http: <//www.ibge.gov.br/home/presidencia/noticias/imprensa/ppts/000000113637122020123 75418902674.pdf >. Acesso em: 20 nov. 2014a.

INSTITUTO BRASILEIRO DE GEOGRAFIA E ESTATÍSTICA - IBGE. Sala de imprensa. Estatísticas de gênero mostram como as mulheres vêm ganhando espaço na realidade socioeconômica do país. 2014. Disponível em:

<http://saladeimprensa.ibge.gov.br/noticias?view=noticia\&id=1\&busca=1\&idnoticia=2747> Acesso em: 20 nov. 2014 b.

ISHIDA, J. S.; STEFANO, S. R.; ANDRADE, S. M. de. Avaliação da satisfação no ensino de pós à distância: a visão dos tutores e alunos do PNAP/UAB. Avaliação, Campinas; Sorocaba, SP, v. 18, n. 3, p. 749-772, nov. 2013. Disponível em:

<http://www.scielo.br/pdf/aval/v18n3/12.pdf> Acesso em: 05 dez. 2014.

KAY, J. Foundations of corporate success. Oxford: Oxford University, 1993.

LARA, E. EaD - Vantagens da educação a distância. Portal Educação. Campo Grande MS. 2009. Disponível em: <http://www.portaleducacao.com.br/pedagogia/artigos/7671/eadvantagens-da-educacao-a-distancia>. Acesso em: 21 nov. 2014.

MAGNANI, M. Identificação de fatores críticos de sucesso para formulação de estratégias que minimizem a perda de competência organizacional de um centro de $\mathbf{P \& D}$ Agropecuário. 2004. Tese (Doutorado) - UFSC, Florianópolis, 2004. Disponível em: <http://www.alice.cnptia.embrapa.br/alice/bitstream/doc/743749/1/tesemarcio.pdf > Acesso em: 22 maio 2015.

MAIA, C.; J. MATTAR. ABC da EaD: a Educação a Distância hoje. São Paulo: Pearson. 2007.

MAROCO, J. Análise estatística: com utilização do SPSS. 3. ed. Lisboa: Silabo, 2007.

PALLOF, R.; PRATT, K. O aluno virtual: uma guia para trabalhar com estudantes on-line. Porto Alegre: Artmed, 2004.

PETERAF, M. A. The cornerstones of competitive advantage: a resource-based view.

Strategic Management Journal, v. 14, no 3, p. 179-191, 1993. Disponível em: <https://pdfs.semanticscholar.org/5d44/1dd3f5e3467bb242bb6d1417fc1676791001.pdf>. Acesso em: 23 set. 2014. 
PORTER, L. R. Creating the virtual classroom: distance learning with the Internet. New York, USA. John Wiley \& Sons, Inc., 1980.

PRETI, O. Educação a distância: uma prática educativa mediadora e mediatizada. Cuiabá: NEAD/ IE -UFMT, 1996.

REMATAL, D. R. C.; BEHAR, P. A.; MAÇADA, A. C. G. Elementos de gestão para educação a distância: um estudo a partir dos fatores críticos de sucesso e da visão baseada em recursos. Revista Renote - Novas tecnologias na educação. Rio Grande do Sul, v. 7, n. 1, julho, 2009. Disponível em: <http://seer.ufrgs.br/renote/article/view/13974> Acesso em: 12 jul. 2014.

ROCKART, J. F. Chief executives define their own data needs. Harvard Business Review, v. 57, n. 2, mar./abr.1979.

UNICENTRO. Especialização em Gestão Pública Municipal. 2014. Disponível em: $<$ http://ead.unicentro.br/gestaopublicamunicipal/>. Acesso em: 30 out. 2014a.

UNICENTRO. Unicentro tem 27 cursos estrelados no Guia do Estudante. 2013.

Disponível em: <http://www2.unicentro.br/blog/2013/09/01/unicentro-tem-27-cursosestrelados-no-guia-do-estudante/>. Acesso em: 16 nov. $2014 \mathrm{~b}$.

VERGARA, S. C. Projetos e relatórios de pesquisa em administração. São Paulo: Atlas, 2000 .

YIN, R. K. Estudo de caso: planejamento e métodos. 4. ed. Porto Alegre: Bookman, 2010.

Josiani Aparecida Karpinski - Universidade Estadual do Centro-Oeste Guarapuava |PR | Brasil. Contato: jhosyk@gmail.com

Neirisleia Francisconi Del Mouro - Universidade Estadual do Centro-Oeste Guarapuava | PR | Brasil. Contato: leia_delmouro@hotmail.com

Marcos de Castro - Universidade Estadual do Centro-Oeste Guarapuava |PR | Brasil. Contato: marcosdecastroms@yahoo.com.br

Luiz Fernando Lara - Universidade Estadual do Centro-Oeste Guarapuava |PR | Brasil. Contato: lflara2010@yahoo.com.br 